\title{
Trends and Overview Regarding the Involvement of Micro-Grids in Modern Power Systems
}

\author{
Muhammad Ali ${ }^{1}$, Hafeez ur Rahman ${ }^{2}$, Waheed ur Rahman ${ }^{1}$, Haseeb ur Rahman ${ }^{1}$ \\ ${ }^{1}$ Deparment of Electrical Engineering, NWFP University of Engineering \& Technology, Peshawar, Pakistan; ${ }^{2}$ Department of Elec- \\ trical Engineering, Gandhara Institute of Science \& Technology, Peshawar, Pakistan. \\ Email: mohammad-a@live.com
}

Received February $1^{\text {st }}, 2012$; revised March $9^{\text {th }}$, 2012; accepted March $17^{\text {th }}, 2012$

\begin{abstract}
Customer satisfaction and participation in utility supply packages is the first and foremost factor in the success of any supplying agency whether wholesale or retail dealer. The paper presents the concept of major prospects of non- autonomous micro-grids installed in a certain locality. The article shows the basic background that is required for the installment of micro grid in a particular area and discusses the primary factors or pre-requisites that are required for the existence and operation of micro-grids. It elaborate the major profitable applications and benefits that developing and developed states get by using micro-grids in an area where utility grid is already functioning. It also explains the basic improvement in the quality of supply from micro grid after its installment. It also throws light on afterwards impact on society with this system, such impacts include reliability, tariff rates, economics etc. The article discusses micro-grids as the future of modern power systems. This paper shows significance of modernization by latest topologies in power systems and its effect that will come afterwards.
\end{abstract}

Keywords: Distributed Generation (DG); Micro-Grids (MG); Renewable Energy Resources (RER); Micro-Grid Central Controller (MGCC); Local Controller (LC)

\section{Introduction}

Every equipment either residential or industrial runs through electrical power. As technologies advances; the need of power is increasing drastically. Centralized power systems for generation thus produces fluctuations at load side as demand is not being fulfilled properly and this basic need is increasing rapidly, thus utilities feel a great pressure on them for increasing generation [1] and transmission lines. Consumers are not satisfied fully by the present scenario of available power especially in developing countries. So, Distributed Generation is one the basic means of generating power for a certain locality, which is environmental friendly as it minimizes the emissions of hazardous gases. MG consists of power generators capable of power generation rang from several KW to few MW using Renewable Energy Resources such as solar, wind, biomass etc and can run on fossil fuels such as coal, gas, oil etc. Operation of Micro-Grids can be performed in two basic modes. One form of operation is in autonomous mode and other form of operation is in non-autonomous mode as shown in Figures $\mathbf{1}$ and $\mathbf{2}$. Autonomous operation [2] is that the MG is operating alone or in other words it is decoupled from electrical utility. Second form of operation is in non-autonomous mode in which MG acts as a stand by system with

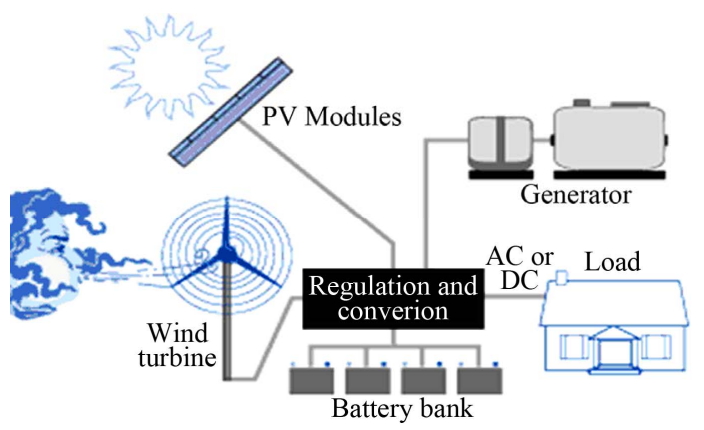

Figure 1. Centralized power system.

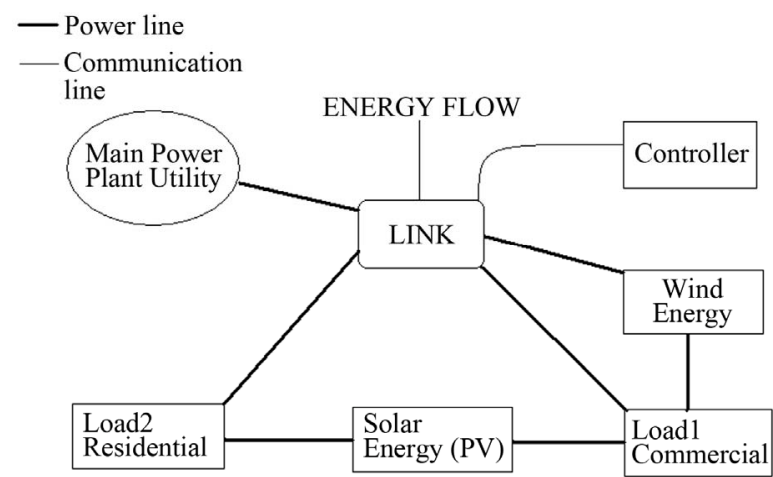

Figure 2. Distributed power system. 
electrical utility. These DG sets are installed with electrical utility to provide strength $[3,4]$ to power plant by supporting its voltage level or by supporting power for reducing the peak demand during certain times. Stand-by power generating units with present electrical infrastructure can be used for micro-grids. MG can prove to be one of the best choice for installing it in a certain locality, provided that it costs low and also in provides a certain acceptable level of reliability [5] for a fighting with present electrical utilities in modern age. The trends of MG are enormously rising as they share some basic load from utility. This basic trend is growing especially growing in developing counties where RER are sufficient to generate the demands of people alone as well as by sharing with utility. The basic and the foremost specialty of MG's is that they can operate in Islanding mode [6] thus provides safety against troubling effects of faults. This paper is divided into three main phases. Phase one shows the basic background that is required for the installment of micro grid in a particular area. This section discusses the primary factors or pre-requisites that are required for the existence and operation of micro-grids. Phase two elaborates the major profitable applications and benefits that developing and developed states get by using microgrids in an area where utility grid is already functioning. Final phase explains the basic improvement in the quality of supply from micro grid after its installment.

The decentralized generation of electricity infrastructure near to load using distributed generation [7].

In decentralized approach DG source controller [8] is mainly responsible for power management. DG source controller is called Local controller and micro-grid central controller is connected with Local controller for power management from main utility.

In the Figure 3 intelligent TCP/IP controller network figure electrical utility is connected through micro-grid central controller and local controller.

In peak hour of demand intelligent local controller which is connected by TCP/IP networking cable send request to micro-grid central controller through TCP/IP communication protocol. In Figure 3 TCP/IP controller network Intelligent MGCC check the available power from Utility that can supply to load through local controller and Local controller control the power supply to load. If power required to load is available power that can be supply to load then MGCC send a signal to local controller and starts sending power to load through LC. If more power required then local controller send request to other local controller to send the power. In case of power requirement is not fulfill then intelligent local controller perform intelligent load Shedding.

The ultimate objective is to provide the smooth and reliable power supply to load in different circumstances. Different types of "intelligent load shedding" [9-12] scheme have been discussed in literature for power management.

In [13] describe the decentralized software control approach with intelligent agents the on FIPA software where the local controllers compute one other to optimize MGCC operation of MG.

This report stresses on non-autonomous mode of microgrids with direct connection with electrical utility. Figure $\mathbf{4}$ shows the architecture of micro grid with direct connection with utility through point of common connection.

\section{Phase-1: Technical Background}

Following are the important pre-requisites required for the existence of micro-grids in a certain area:

For running MG on fossil fuels such as natural gas, coal etc it is very vital that any of these resources must be present in excessive amount in that particular area where MG is to be installed. Once MG starts functioning it requires fuel from time to time for generation. So, for any region complete feasibility of resources in particular

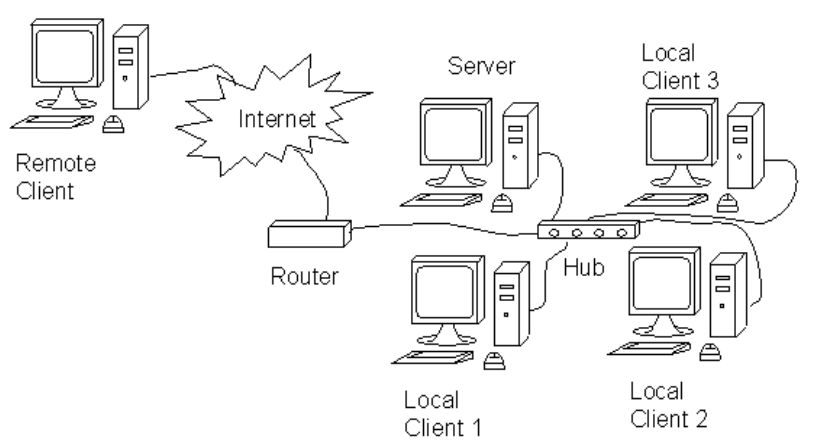

Figure 3. TCP/IP controller network.

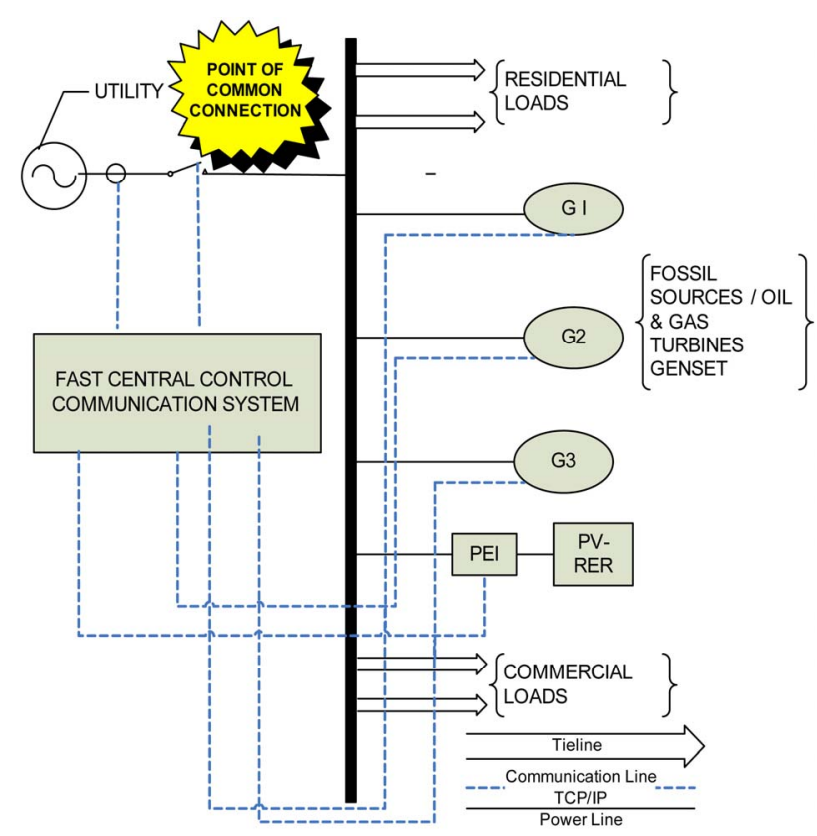

Figure 4. Non-autonomous MG architecture. 
area must be done. Calculations must be done for how much time resources can last? And after that time what strategy either economic or uneconomic is adopted or in other sense, either it will be feasible to run MG after that period or not?

Do the climatic as well as geographic conditions agree for the installment of MG? For example for an area which is mostly gathered by clouds so, Photo Voltaic MG alone installment is a big question. For an area, where rain occurs most of the time in a day and throughout the year, so, wind operated MG is out of question. MG is very feasible in urban areas and its nearby surroundings where all facilities e.g. transportation etc are available. But for rural areas, MG is still a big issue.

When in any particular area, load is increasing tremendously with only present old dated generation system available there, due to which there exists a remarkable difference between generation and supply, so, non-autonomous MG is a best solution. As a result, due to lack of facilities and unawareness, crews of that electrical grid have only one solution to that particular problem and that unacceptable solution is load shedding. This is because present generation system of the grid is unable to meet the increasing demands of the people. MG in that area could share some effective load from grid thus improving power quality of supply.

For a region where blackouts or load shedding is unacceptable in any case even for few minutes such as emergency hospitals, operation theater, university research labs etc so, MG connection with utility will be most suitable case .

Reliability and economics are the big issues associated with utility. Also power quality is another important issue with grids. When demands are increasing and suppliers are not getting much from consumers so result will be a massive tariff rate. Sensitive electronic instruments efficiency greatly rely on power quality of supply. Present UPS setup produce fluctuations to load as well as it has low electric density as compared to grid power because there are enough losses during conversion process of energy.

The most important issue especially for developing state is that due to increased demand and time to time load shedding people have owned their mini-generators diesel sets for shops and homes. They are facing problems like power. The cost on its operation, fuel, maintenance etc becomes a big problem for local people. People in an underdeveloped state does not know how to earn a great profit form this mini set by exporting power from this set to utility as well as to the market. For this, it requires a control infrastructure of Non-Autonomous MG for distribution. Due to lack of infra structure, the practical implementation of this system is still a big question. Also, developed states cannot bear interruptions in sup- ply and power converted from batteries in acute emergency cases has low electric density as compared MG operating on fossil fuels maintenance, operation, economics etc. People use these small sets only for acute emergency cases in the times of load shedding otherwise their demand is fulfilled partially by grid. However The major issues for DG operation is control, protection, stability and power quality of the supply $[14,15]$.

\section{Phase-2 Profitable Benefits and Applications}

The most promising feature of MG is the establishment of business industry that can worth millions and billions of dollars for providing back up power and support to masses. With well equipped setup it is capable of exporting the power to utility and to some required residential areas as well as to some private sector. Thus, it provokes thirsty businessmen to invest money in this sector and can earn healthy profit. For example in a certain community of 10 - 15 houses there exists a MG setup and each owner of the house has to buy a membership of MG for backup power. So, in case of failure of delivery from utility MG provides its members quality power for certain time. Each member has to pay to MG owner who gains profit through exporting power to residential sector and to utility in times of need.

By the implementation of MG, the cost/KWhr of used power from MG is reduced to a suitable value as compared to market value of electricity produced by central power plant. The costs involving installation, maintenance, operational etc are much reduced as compare to large utility setup including large units, long transmission lines and increase losses due to corona; hurricanes etc. This mini setup is close to loads so losses are much reduced in this case.

The concept of MG minimizes a lot of risks to electrical utilities. These risks include fault occurring in central plant, in transmission lines, in MG. Thus, it adds a security feature to utility while operating in non-autonomous mode as it is capable of operating in an islanded mode. During heavy loading conditions MG can be subjected to intentional or emergency islanding. Other types of risks include load forecasting, prices of the fuel regularity issues etc. MG smaller units requires less project capital and lead time compared to large and heavy utility units.

By utilizing renewable energy resources (RER) such as solar, wind etc in MG topology results in environmental friendly atmosphere protecting ozone layer. By using these sources one (developing or developed state) is totally free from importing fossil fuels for production. Thus, a state can store and reserve its primary energy resources for times of acute emergency. This concept can save a lot of money being spent on importing fuels from 
other states.

Through the implementation of this system unemployment is considerably reduced in a particular area of the state as MG introduces job opportunities for the unemployed people.

For using MG in cogeneration mode, the waste heat produced can be used for heating, cooling in chemical industries and hospitals. With MG if small units become faulty can be easily resold and displaced from one place to another as compared to large central power plant.

MG provides supporting and control services to utility such as:

- By the injection/absorption of reactive power for controlling voltage of grid.

- Can act as spinning reserve.

- Can provide network stability.

- Avoid system blackouts.

- By the control of regulation etc.

\section{Power Quality of Micro-Grids}

In power systems, a term power quality is a quality of service issued for customer and electric power service providers. This term basically covers a variety of transient electromagnetic phenomenon [16]. The issues of power quality are pronounced in modern power systems especially in distributed generation, its importance is very vital. Several problems may occur in power systems such as blackouts, outages, surges etc. These basic problems occur due to power imbalance and increased demand than supply. So, large variations and fluctuations in supply are encountered in large power systems. Power quality issues also includes current distortion, power factor, harmonics and triple harmonics, transients, Ferro resonance, dropouts, sags, flicker, swell, reverse recovery voltages, islanding etc. All above issues if not handled properly may lead to poor service quality of supply. The useful life of power system equipment is going towards decline due to poor service quality provided by service managers [17].

In real power quality problems is normally related to hardware, software or control system malfunction of power system. In system due to repeated Transient voltages the Performance of equipments can be degrade over the period of time. A survey conducted results on the causes of power quality problems by Georgia power co. given below. The power quality can have direct economic Impact on many industrial users. Power quality is also important issue because meeting the consumer expectation and increase customer confidence by increasing power quality. Figures 5 and $\mathbf{6}$ survey results [18] conducted by Georgia Power Co. of customer and Utility perception causes of power quality.

The concept of non-autonomous MG introduced here

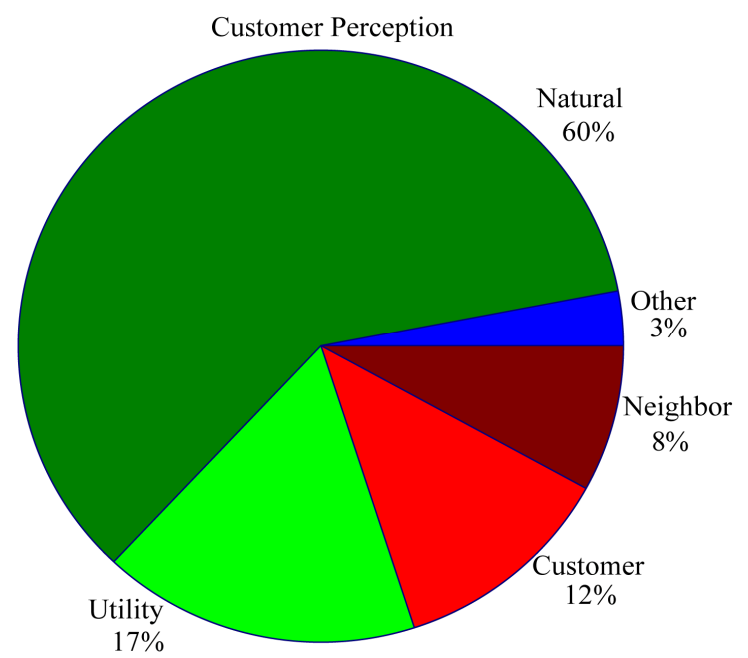

Figure 5. Survey results (conducted by Georgia power co.).

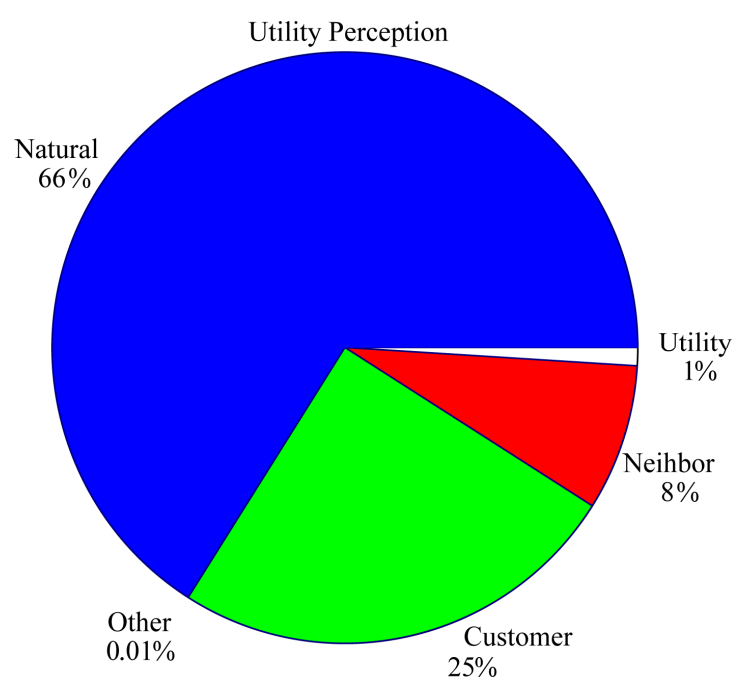

Figure 6. Survey results (conducted by Georgia Power co.).

eliminates some of major power quality issues such as blackouts, Ferro resonance, Increased surges etc. Since MG is the form of DG in power systems capable of handling load according to its rating and supply. It maintains power, voltage and frequency balance with utility interconnected. The quality of supply is judged at consumer end and proper maintenance of supply for different type of consumers. MG eliminates and defers interruptions in supply by sharing load from utility, acting as a backup or a standby system. Different MGs in cases of acute emergencies are capable of operating in islanding mode in interconnected power systems. Each island maintains its continuous supply to each connected consumer end and when risks are removed again linked to central power system or utility. In intentional islanding mode the system of islanding has been planned in advance and all the equipments have been designed to cope with the situation. During hurricane or weather disturbances MG isolates 
itself from the utility supply. Thus by doing this it avoids the risks of disturbances due to lighting strokes either direct or indirect and other faults affecting the ongoing supply. For example, in hospitals when open-heart surgery is taking place interruptions in any case is highly unacceptable. In unintentional mode, power system is heavily loaded which can result in large fluctuations of voltage and frequency resulting in the malfunctioning of consumer equipments. MG is thus subjected to unintentional islanding to avoid all this and maintains quality supply to its connected loads.

Micro-grid can increase efficient service quality by providing power generation redundancy whenever needed. In cases of extreme demand and loading conditions it enhances security of upstream networks against faults and risks by operating in emergency iswlanding mode. MGs as LV networks provide quality and reliable power in contrast to heavy loaded HV networks [19]. In power systems, power quality disaster level can be expressed as overall losses caused by power quality events. Power quality disaster level can be expressed as,

$$
E=\sum n_{k}\left(c_{F k} \bar{E}_{F k}+c_{L k} \bar{E}_{L k}\right)
$$

where subscript k power quality event type:

$E$ : Overall losses of all the power quality disasters during monitoring period;

$n$ : Number of power quality events;

$\bar{E}_{F k}$ : Average direct loss of power quality events;

$c_{F k}$ : Correction coefficient of average direct loss;

$\bar{E}_{L k}$ : Average latent loss of power quality events;

$c_{L k}$ : Correction coefficient of average latent loss.

$$
\bar{E}_{F k}=\frac{\sum_{j} F_{F k j}}{n_{k}}, \quad \bar{E}_{L k}=\frac{\sum_{j} F_{L k j}}{n_{k}}
$$

Power quality disaster level if increased may result in a high loss to utility or facility managers. The chances of power transmission collapse is less in decentralized systems especially in DG. As MG has fewer number of connected loads and this system is interconnected with utility so micro grid central controller avoids such dangerous consequences by immediate action of islanding. So, power quality is improved as well as disaster level is minimized.

\section{Conclusion}

This paper has discussed Micro-grid technology playing a more numerous and important role in the world's energy demand. Micro-grid safe operation increase chances for fulfill the supply and demand of the consumer. Automated load management technique implemented by intelligent controller (neural implementation of controller) network provides opportunity to overcome energy imbalance. It further discussed the idea of non-autonomous micro grid presented here can benefit utility, society and local people of a certain locality. By implementing this system losses are reduced, quality of power is improved much better, tariff rates are reduced that can benefit poor people and avoids interruption in supply that can benefit critical places such as hospitals.

\section{REFERENCES}

[1] B. Renders, L. Degroote, J. Driesen and L. Vandevelde, "Profits of Power-Quality Improvement by Residential Distributed Generation," The 42nd International Universities Power Engineering Conference, Brighton, 4-6 September 2007, pp. 377-381.

[2] J. F.G. Cobben, W. L. Kling and J. M. A. Myrzik "Power Quality Aspects of a Future Micro Grid,” International Conference on Future Power Systems, Amsterdam, 16-18 November 2005, pp. 1-5.

[3] P. A. Daly and J. Morrison "Understanding the Potential Benefits of Distributed Generation on Power Delivery Systems,” Rural Electric Power Conference, Little Rock, 29 April-1 May 2001, pp. 211-213.

[4] V. H. M. Quezada, J. R. Abbad and T. G. S. Roman, “Assessment of Energy Distribution Losses for Increasing Penetration of Distributed Generation,” IEEE Transactions on Power Systems, Vo. 21, No. 2, 2006, pp. 533-540. doi:10.1109/TPWRS.2006.873115

[5] P. M. Costa and M. A. Matos, "Reliability of Distributed Networks with Micro-Grids,” IEEE Russia Power Tech, St. Petersburg, 27-30 June 2005, pp. 1-7.

[6] N. Hatziargyriou "MICROGRIDS-Large Scale Integration of Micro Generation to Low Voltage Grids," First International Conference on "Integration of RES and DER", Brussels, 1-3 December 2004,

[7] M. W. Davis, "Distributed Resource Electric Power Systems Offer Significant Advantages over Central Station Generation and T\&D Power Systems, Part I,” IEEE T\&D Conference and Exposition, Atlanta, 25 July 2001, pp. 54-61.

[8] N. Hatziargyriou, A. Dimeas and A. Tsikalakis "Hierarchical and Distributed Control Strategies for Micro-Grids," International Journal of Distributed Energy Sources, Vol. 1, No. 3, 2005.

[9] A. Maiorano, R. Sbrizzai, F. Torelli and M. Trovato, "Intelligent Load Shedding Schemes for Industrial Customers with Cogeneration Facilities,” Power Engineering Society Winter Meeting, New York, 31 January-4 February 1999, pp. 925-930.

[10] D. Novosel and R. L. King, "Using Artificial Neural Networks for Load Shedding to Alleviaie Overloaded Lines," IEEE Transactions on Power Delivery, Vol. 9, No. 1, 1994, pp. 425-433.

[11] L. J. Shih, W. J. Lee, J. C. Gu and Y. H. Moon, “Application of df/dt in Power System Protection and Its Implementation in Microcontroller Based Intelligent Load Shedding Relay,” Industrial and Commercial Power Systems Technical Conference, Memphis, 6-9 May 1991, pp. 11-17.

[12] W. J. Lee and J. C. Gu, “A Microcomputer-Based Intelligent Load Shedding Relay,” IEEE Transactions on Power 
Delivery, Vol. 4, No. 4, 1989, pp. 2018-2024.

[13] R. Lasseter, A. Akhil, C. Marnay, J. Stephens, J. Dagle, R. Guttromson, A. Meliopoulos, R. Yinger and J. Eto, "White Paper on Integration of Distributed Energy Resources. The CERTS MicroGrid Concept,” Consortium for Electric Reliability Technology Solutions (CERTS), Berkeley, 2002.

[14] D. Trudnowski, A. Gentile, J. Khan and E. Petritz, "FixedSpeed Wind Generator and Wind-Park Modeling for Transient Stability Studies," IEEE Transactions on Power System, Vol. 19, No. 4, 2004, pp. 1911-1917. doi:10.1109/TPWRS.2004.836204

[15] E. Muljadi and H. McKenna, "Power Quality Issues in a Hybrid Power System," IEEE Transactions on Industry Applications, Vol. 38, No. 3, 2002, pp. 803-809.
doi:10.1109/TIA.2002.1003433

[16] J. Arrillaga, M. H. J. Bollen and N. R. Watson, "Power Quality Following Deregulation,” Proceedings of the IEEE, Vol. 88, No. 2, 2000, pp. 246-261. doi:10.1109/5.824002

[17] R. Ghandehari and A. Jalilian, "Economical Impacts of Power Quality in Power Systems,” Iran University of Science \& Technology (IUST), Tehran, pp. 893-897.

[18] R. C. Dugan, M. F. McGranaghan, S. Santoo and H. W. Beaty, "Electrical Power System Quailty,” McGraw-Hill Prof Med/Tech, Boston, 2012.

[19] Y. Zhu, Y. Liu, Y. Xu and X. Xiao "Evaluation of Disaster Level caused by Power Quality Problems,” School of Electrical and Electronic Engineering, North China Electric Power University, Beijing, pp. 233-235. 